PANCREATIC CANCER

\title{
Altered glucose metabolism and proteolysis in pancreatic cancer cell conditioned myoblasts: searching for a gene expression pattern with a microarray analysis of 5000 skeletal muscle genes
}

\author{
D Basso, C Millino, E Greco, C Romualdi, P Fogar, A Valerio, M Bellin, C-F Zambon, F Navaglia, \\ N Dussini, A Avogaro, S Pedrazzoli, G Lanfranchi, M Plebani
}

Gut 2004;53:1159-1166. doi: 10.1136/gut.2003.024471

See end of article for authors' affiliations

Correspondence to: Dr M Plebani, Department of Laboratory Medicine, University-Hospital, Via

Giustiniani 2, 35128

Padova, Italy;

mario.plebani@

sanita.padova. it

Accepted for publication 3 February 2004

\begin{abstract}
Background and aims: We verified whether conditioned media (CM) from pancreatic cancer cell lines (MIAPaCa2, CAPAN-1, PANC-1, BxPC3) alter glucose metabolism and gene expression profiles (microarray experiment with a platform of 5000 skeletal muscle cDNA) in mice myoblasts.

Methods: Myoblasts were incubated with control or pancreatic cancer CM for 24 and 48 hours.

Results: Lactate significantly increased in CM compared with non-conditioned myoblasts. No variations in expression levels of the main genes involved in glycolysis were found in CM myoblasts. Propionyl coenzyme A carboxylase and isocitrate dehydrogenase 3 beta genes, which encode enzymes of the tricarboxylic acid cycle, were overexpressed, while IGFIIR and VAMP5 genes were underexpressed in CM myoblasts. PAFAH1B1 and BCL-2 genes (intracellular signal transduction) and the serine protease cathepsin $\mathrm{G}$ (proteolysis), were overexpressed in CM myoblasts. Tyrosine accumulation in CM myoblasts suggested that proteolysis overcomes protein synthesis. Sorcin, actin alpha, troponin $\mathrm{Tl}$, and filamin A were underexpressed in CM myoblasts.

Conclusions: Our findings demonstrate that pancreatic cancer cell conditioned media enhanced lactate production and induced proteolysis, possibly by altering expression levels of a large number of genes, not only those involved in protein biosynthesis and degradation or glucose metabolism, but also those involved in the tricarboxylic acid cycle and in vesicle traffic.
\end{abstract}

A clinical history of recently diagnosed type 2 diabetes is often found in patients with pancreatic adenocarcinoma. ${ }^{1-3}$ Epidemiological data suggest that type 2 diabetes is either a risk factor for pancreatic adenocarcinoma ${ }^{2-6}$ or a metabolic impairment strictly associated with and consequent to pancreatic adenocarcinoma itself. ${ }^{78}$ Although the two hypotheses are not mutually exclusive, the latter is supported by a body of clinical and experimental data $^{139-14}$ : sudden onset type 2 diabetes is usually found in patients with pancreatic cancer ${ }^{238}$ and tumour excision either ameliorates glucose tolerance or leads to complete remission of diabetes. ${ }^{19}$ Furthermore, in vivo and in vitro experimental studies indicate that pancreatic cancer cell products can alter liver and muscle glucose metabolism and can induce peripheral insulin resistance. ${ }^{9-11} 1415$

Pancreatic cancer cell conditioned media (CM) reduce liver glycolysis and favour the triglyceride synthesis pathway. ${ }^{14}$ Pancreatic tumour extracts from type 2 diabetic patients reduce skeletal muscle glycogen storage, ${ }^{9}$ possibly enhancing glycogen phosphorylase, while reducing glycogen synthase, mRNA, and enzyme activities. ${ }^{15}$ Pancreatic cancer has also been reported to cause an altered beta cell response to physiological stimuli ${ }^{16}$ and dissociation between insulin and amylin secretion. ${ }^{12} 1317$

It has been suggested that rapidly evolving cachexia, another feature of pancreatic cancer, is caused by tumour cell products, particularly the proteolysis inducing factor, which is released into the bloodstream, targeting muscle cells. ${ }^{18-21}$

The skeletal muscle mass therefore appears to be significantly involved in patients with pancreatic cancer, being the potential target of various tumour products which can alter glucose metabolism on the one hand and activate protein degradation on the other.

The aims of this study were to verify whether pancreatic cancer cell CM alter glucose metabolism in mice myoblasts and to compare the gene expression profiles of nonconditioned and conditioned myoblasts using a microarray experiment with a platform of 5000 skeletal muscle cDNA.

\section{EXPERIMENTAL PROCEDURES}

\section{Cell cultures}

We used four human pancreatic cancer cell lines: two (MIA PaCa 2 and CAPAN-1) were obtained from the American Type Culture Collection (ATCC), PANC-1 was a gift from Professor A Scarpa (University of Verona, Italy), and BxPC3 was kindly provided by Dr A Galli (University of Florence, Italy). The colorectal cancer cell line HT29 was obtained by Deutsche Sammlung von Mikroorganismen und Zellkulturen $\mathrm{GmbH}$ (DSMZ). The myogenic mice cell line $\mathrm{C}_{2} \mathrm{C}_{12}$ was obtained from frozen batches maintained in our laboratories. MIA PaCa 2, PANC-1, and BxPC3 cells were established from human primary pancreatic adenocarcinomas whereas CAPAN-1 cells were established from a liver metastasis from a pancreatic ductal adenocarcinoma. Cells were kept in

Abbreviations: CM, conditioned media; DMEM, Dulbecco's modified Eagle's medium; FCS, fetal calf serum; PBS, phosphate buffered saline; NCM, non-conditioned medium; TC, tumour conditioned; MW, molecular weight; RT-PCR, reverse transcription-polymerase chain reaction; ECHS1, enoyl coenzyme A hydratase; IGF2R, insulin-like growth factor 2 receptor; VAMP5, vesicle associated membrane protein 5; FLNA, filamin A; PCCB, propionyl coenzyme A carboxylase; RPS16, ribosomal protein $\mathrm{S} 16$ 
culture $\left(75 \mathrm{~cm}^{2}\right.$ flasks $)$ at $37^{\circ} \mathrm{C}$ in a humid atmosphere, with $5 \% \mathrm{CO}_{2}$ and $95 \%$ air. MIA PaCa 2, BxPC3, HT29, and $\mathrm{C}_{2} \mathrm{C}_{12}$ cells were grown in Dulbecco's modified Eagle's medium (DMEM, 0.1\% gentamycin and 10\% fetal calf serum (FCS); reagents from Life Technologies, Paisley, UK). PANC-1 were grown in RPMI (Life Technologies, Paisley, UK) $(0.1 \%$ gentamycin and 10\% FCS) whereas CAPAN-1 cells were grown in RPMI (0.1\% gentamycin and $20 \%$ FCS). Pancreatic and colorectal cancer cell line CM were obtained as follows: 400000 cells were plated in $75 \mathrm{~cm}^{2}$ flask and cultured for seven days in low glucose (5.5 mM) DMEM (0.1\% gentamycin and 10\% FCS). The media were then collected, centrifuged at $1100 \mathrm{~g}$, and stored at $4^{\circ} \mathrm{C}$ for no more than 24 hours, after which the experiments with myoblasts were performed.

\section{Patient tumour samples}

Neoplastic tissue samples were obtained at surgery from six patients (two males, four females; aged 50-75 years) with locally advanced pancreatic adenocarcinoma: three had type 2 diabetes (fasting plasma glucose $>126 \mathrm{mg} / \mathrm{dl}$ ). Samples were stored at $-80^{\circ} \mathrm{C}$ for no more than two months. Each tissue sample was homogenised in phosphate buffered saline (PBS $1: 20 \mathrm{w} / \mathrm{v}$ ) and total protein content was measured (Bradford's method; BioRad Laboratories GmbH, Munchen, Germany).

\section{Experiments with mice myoblasts}

Sixty thousand myoblasts were plated in each well of a 24 culture plate and cultured for 24 hours. The medium was removed; after washing with PBS, myoblasts were incubated in a non-conditioned medium (NCM $=$ DMEM $(0.1 \%$ gentamycin, and $10 \%$ FCS)), in pancreatic or colorectal cancer cell CM, or in NCM with tumour tissue homogenates ( $\mathrm{TC}=$ tumour conditioned $)$ reaching a final tumour derived protein concentration of $1 \mathrm{mg} / \mathrm{ml}$. Glucose and lactate concentrations of NCM, CM, and TC were measured and corrected before the experiments in order to obtain the same starting values. The experiments were performed at a glucose concentration of $20 \mathrm{mM}$. Media were collected after 24,48 and, in some experiments, 72 hours. All the experiments were done at least in triplicate.

\section{Experiments with mice myoblasts and $\mathrm{U}-{ }^{13} \mathrm{C}$-glucose} Three separate experiments using mice myoblasts incubated with NCM and pancreatic cancer cell line CM were made using U- ${ }^{13} \mathrm{C}$-glucose (Tracer Technologies INC, Sommerville, Massachusetts, USA) (2\% of native ${ }^{12} \mathrm{C}$-glucose) in order to follow its metabolic fate through $3-{ }^{13} \mathrm{C}$-lactate enrichment. Supernatants were collected after 24, 48, and 72 hours. Samples were immediately frozen and stored at $-20^{\circ} \mathrm{C}$ until $3-{ }^{13} \mathrm{C}$-lactate and $5-{ }^{13} \mathrm{C}$-glucose were analysed.

\section{Experiments with mice myoblasts and fractioned CAPAN-1 conditioned medium}

A series of three separate experiments were performed with NCM myoblasts and myoblasts incubated with CAPAN-1 CM and with three fractions of the latter, obtained after ultrafiltration with DIAFLO 10000 molecular weight (MW) and $30000 \mathrm{MW}$ (Amicon Millipore Corporation, Bedford, Massachusetts, USA). Fractions were: (1) MW <10 000 Da; (2) MW 10 000-30 000 Da; and (3) MW >30 000 Da.

\section{Biochemical analyses}

Total glucose and lactate were measured within three hours from collection by means of a colorimetric method on an automatic analyser (Dimension RxL, Dade Behring, Milan, Italy).

Lactate production, derived from glucose, and glucose utilisation $\left(3-{ }^{13} \mathrm{C}\right.$-lactate from $\mathrm{U}-{ }^{13} \mathrm{C}$-glucose and $5-{ }^{13} \mathrm{C}$-glucose) were analysed as a N-methyl-N-ter-butyldimethylsilyltrifluoroacetamide derivative (Pierce, Rockford, Illinois, USA) and as pentacetate derivative (Sigma Chemical, St Louis, Missouri, USA) respectively, using a quadruple gas chromatography-mass spectrometry instrument, operating in EI mode with an Agilent 5973 Network after separation in a DB-17 capillary column (J\&W, Folsom, California, USA). ${ }^{22}$ The ratio between tracer $\left(3-{ }^{13} \mathrm{C}\right.$-lactate from $\mathrm{U}^{13} \mathrm{C}$-glucose $)$ and tracee $\left(3-{ }^{12} \mathrm{C}\right.$-lactate from natural ${ }^{12} \mathrm{C}$-glucose) mass in the samples was evaluated by isotope ratio measurement (m/z 264/261). The ratio between tracer $\left(\mathrm{U}^{13}{ }^{13} \mathrm{C}\right.$-glucose) and tracee $\left({ }^{12} \mathrm{C}\right.$-glucose $)$ mass in the samples was evaluated by isotope ratio measurement (m/z 247/242). The fragment that represents glucose labelled species resulted with five ${ }^{13} \mathrm{C}$ atoms $\left(2-3-4-5-6-{ }^{13} \mathrm{C}\right.$ glucose) and is monitored at $247 \mathrm{~m} / \mathrm{z}$. The ratio between tracer and tracee mass is evaluated from isotope ratio measurements as:

$\mathrm{g} \times \mathrm{G}^{*} / \mathrm{l}+\mathrm{G}^{*}$ or $\mathrm{L}=1 \times \mathrm{L}^{*} / \mathrm{l}+\mathrm{L}^{*}$

where $G^{*}$ is the tracer glucose concentration from exogenous source, $g$ is the tracee glucose concentration from endogenous source, $\mathrm{L}^{*}$ is the tracer lactate from glucose, and $l$ is lactate from endogenous source.

Using a high pressure liquid chromatography procedure, tyrosine concentrations were measured in the supernatants of NCM and pancreatic cancer cell line CM obtained from three separate experiments.

\section{Myoblasts experiments for microarray analysis}

Mice $\mathrm{C}_{2} \mathrm{C}_{12}$ myoblasts $\left(1.5 \times 10^{6}\right)$ were plated in Petri dishes $(=10 \mathrm{~cm})$ coated with $1 \%(\mathrm{w} / \mathrm{v})$ type A gelatin from porcine skin (Sigma, Milano, Italy).

A total of 80 Petri dishes were prepared, and myoblasts were cultured for 24 hours. Myoblasts from 20 Petri dishes were scraped and pooled (basal); media were removed from the remaining 60 Petri dishes, myoblasts were washed with PBS, and then incubated with NCM (20 Petri) or CAPAN-1 CM (40 Petri). After 16 hours of incubation, media were collected from 10 NCM and 20 CAPAN-1 CM while myoblasts were scraped and pooled. For the remaining 30 Petri dishes, this procedure was repeated after 26 hours of incubation. Glucose and lactate in the supernatants were measured. Total RNA from myoblasts was purified following the Trizol standard protocol. A small aliquot of RNA (200 ng) was then used for quantification and quality control, using the RNA 6000 LabChip kit and Agilent Bioanalyzer 2100 (Agilent Technologies, Palo Alto, California, USA). We routinely obtain a mean quantity of $1 \mu \mathrm{g}$ of total RNA per $10^{5}$ myoblasts. Total RNA $(15 \mu \mathrm{g})$ was retrotranscribed and directly labelled in the presence of Cy3 or Cy5 modified dCTP.

\section{Microarray fabrication}

The microarrays used for this work (http://muscle.cribi.unipd. it/microarrayindex.html) were constructed by arraying polymerase chain reaction (PCR) amplified c-DNAs obtained from our archive of recombinant bacterial clones, on glass slides. This archive consists of 5000 different clones collected after systematic sequencing of skeletal muscle cDNA libraries containing only the $300-500 \mathrm{bp} 3^{\prime}$ portions of muscle transcripts. ${ }^{23}$

\section{Microarray hybridisation}

Microarray hybridisation was carried out in a dual slide chamber (HybChamber; GeneMachines, San Carlos, California, USA), humidified with $160 \mu \mathrm{l}$ of $3 \times$ SSC. Labelled cDNA was dissolved in $35 \mu$ of the hybridisation buffer, denatured at $95^{\circ} \mathrm{C}$ for three minutes in a thermal cycler, and applied on the microarray slides presaturated by incubation with hybridisation buffer (Northern Max; Ambion, Austin, Texas, USA) for five minutes at $42^{\circ} \mathrm{C}$. 


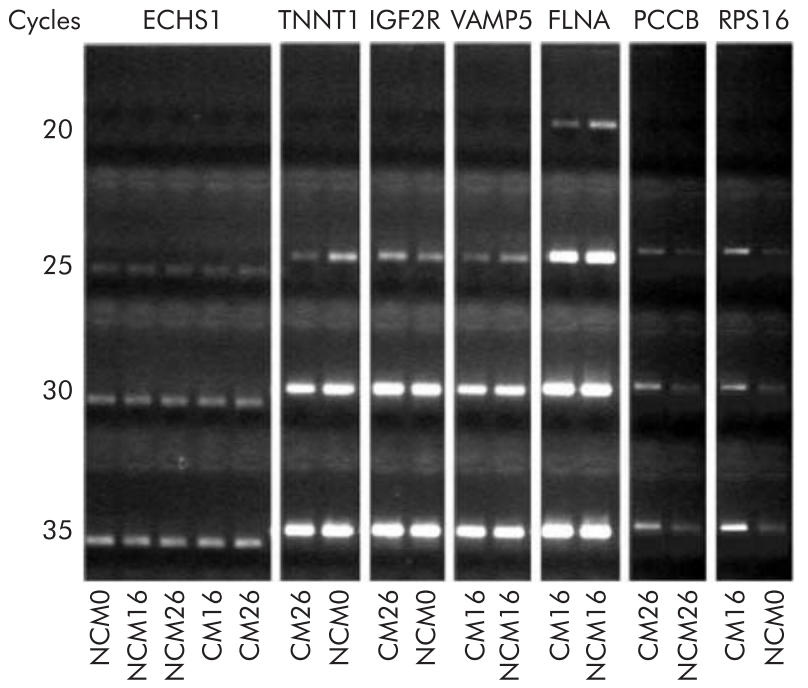

Figure 1 Quantitative reverse transcription-polymerase chain reaction results. Agarose gel electrophoresis of enoyl coenzyme A hydratase (ECHS1), TNNT1, insulin-like growth factor 2 receptor (IGF2R), vesicle associated membrane protein 5 (VAMP5), filamin A (FLNA), propionyl coenzyme A carboxylase (PCCB), and ribosomal protein S16 (RPS16). The starting templates were myoblasts incubated with non-conditioned medium (NCM) or CAPAN-1 conditioned medium (CM) for 0,16 , and 26 hours.

Microarrays were covered with a $22 \times 50 \mathrm{~mm}$ coverslip and hybridised overnight at $42^{\circ} \mathrm{C}$ by immersion in a high precision water bath (W28; Grant, Cambridge, UK). Post-hybridisation washing was performed by serial incubations in buffers with decreasing SSC and SDS concentrations, at $42^{\circ} \mathrm{C}$. Two replicates of each experiment were obtained using different microarray slides in which the sample and reference RNA was labelled either with Cy3 or Cy5; fluorochromes were crossed in both combinations.

Labelled total RNA targets prepared from NCM and CAPAN-1 CM myoblasts, at different time of growth (hours), were used in competitive hybridisations according to the following scheme:

(1) 0 hours NCM versus 16 hours CM myoblasts;

(2) 0 hours NCM versus 26 hours CM myoblasts;

(3) 16 hours NCM versus 16 hours CM myoblasts;

(4) 26 hours NCM versus 26 hours CM myoblasts.

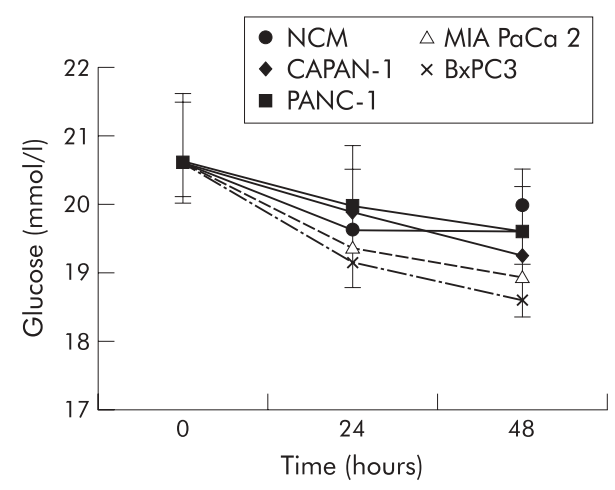

Figure 2 Mean (SD) values for glucose concentrations in nonconditioned (NCM) and pancreatic cancer cell line conditioned myoblasts, obtained after 24 and 48 hours of incubation. Repeated measures analysis of variance: time effects, $p<0.001$; cell lines effects, $p<0.01$; time $\times$ cell lines, $p<0.01$. Bonferroni's $t$ test: $p<0.05$ BxPC3 versus $\mathrm{NCM}$.

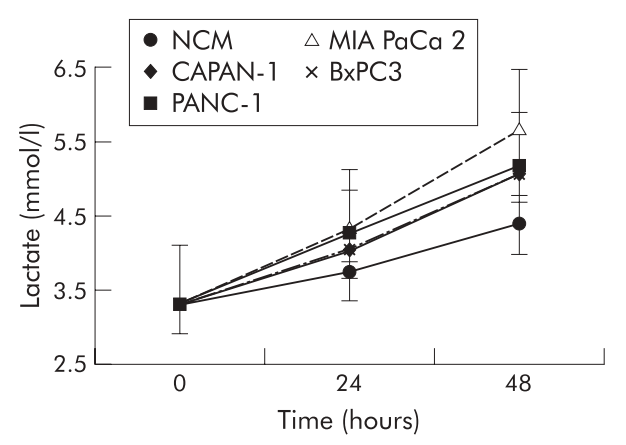

Figure 3 Mean (SD) values for lactate concentrations in nonconditioned (NCM) and pancreatic cancer cell line conditioned myoblasts, obtained after 24 and 48 hours of incubation. Repeated measures analysis of variance: time effects, $\mathrm{p}<0.001$; cell lines effects, $p<0.001$; time $\times$ cell lines, $p<0.001$. Bonferroni's $t$ test: $p<0.05$ CAPAN-1 and PANC-1 versus NCM; $p<0.001$ MIA PaCa 2 versus NCM.

Validation of the relative gene expression profiling by reverse transcription ( $R T)-P C R$

We used quantitative RT-PCR to validate the results obtained from microarray experiments. Total RNA ( $2 \mu \mathrm{g}$ aliquots) from each sample was used to perform three independent cDNA synthesis experiments in a final volume of $20 \mu \mathrm{l}$ using oligodT primer and SuperScript reverse transcriptase (Invitrogen, San Giuliano Milanese, Italy). Gene specific primers were designed using Primer 3 software in order to amplify fragments of approximately $500 \mathrm{bp}$ in length, close to the $3^{\prime}$ end of the transcript. cDNA was amplified in $50 \mu \mathrm{l}$ PCR reactions for a total of 20, 25, 30, and 35 PCR cycles. Each amplicon was electrophoresed on agarose gel and the intensity of the specific bands quantified using a densitometer (GelDoc 2000; BioRad Laboratories, Milano, Italy). Levels of expression were compared with an endogenous control transcript (enoyl CoA hydratase; ECHS1) (fig 1).

\section{Statistical analysis}

Array scanning was carried out using a GSI Lumonics LITE dual confocal laser scanner with ScanArray Microarray Analysis Software, while raw scanner images were analysed with QuantArray Analysis Software (GSI Lumonics, Ottawa, Canada). Normalisation of expression levels was performed with a SNOMAD gene expression data analysis tool, a collection of algorithms directed at the normalisation and standardisation of DNA microarray data, available at http:// pevsnerlab.kennedykrieger.org/snomadnput.html. Before any other statistical analysis, we performed global mean normalisation across microarray surfaces and local mean normalisation across element signal intensity. In single experiments, the mean of the ratio intensity measures of the two replication experiments was calculated and then, after normalisation, $\log _{2}$ transformation was performed for each expression level. In contrast, expression values of the two replicates of each experiment were considered as two separate values, and each was then converted by logarithmic transformation. Principal component analysis was applied using J-express, a Java tool available at www.molmine.com/ index_p.html.

Results were statistically evaluated using one way ANOVA and Bonferroni's test for pairwise comparisons. Repeated measures analysis of variance with interactions was performed using the general linear models procedure. The main effects were time and cell line CM. When the time by cell line interaction was significant $(\mathrm{p}<0.05)$, Bonferroni's $t$ tests of difference between means were performed at the global level of probability of 0.05 (SPSS, version 9.0). 


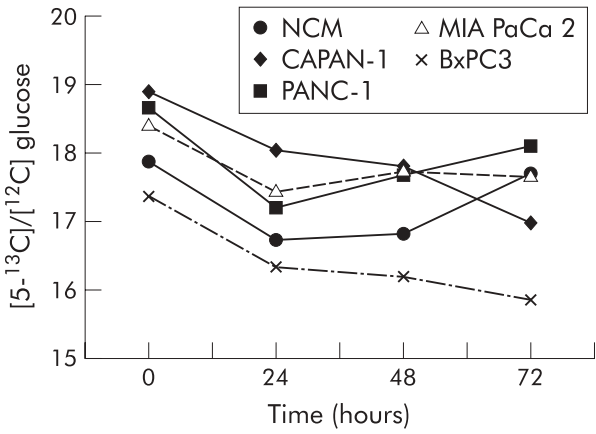

Figure 4 Pattern of $\left[5^{-13} \mathrm{C}\right] /\left[{ }^{12} \mathrm{C}\right]$ glucose (expressed as $247 / 242 \mathrm{~m} / \mathrm{z}$ enrichment) measured from 0 to 72 hours after incubation in nonconditioned (NCM) and pancreatic cancer cell line conditioned myoblasts supernatants. Values are mean. Standard errors were less than $0.5 \mathrm{mmol} / \mathrm{l}$.

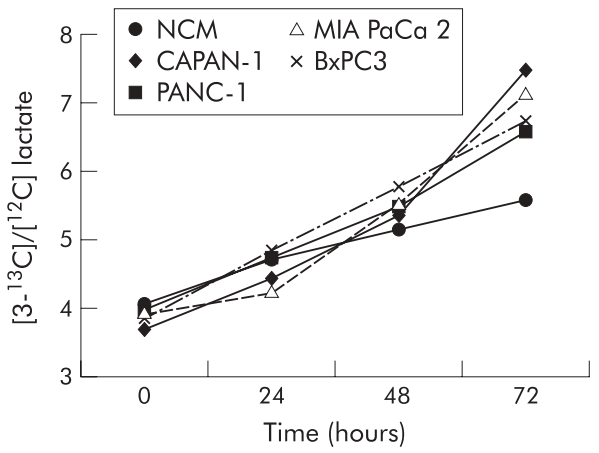

Figure 5 Pattern of $\left[3-{ }^{13} \mathrm{C}\right] /\left[{ }^{12} \mathrm{C}\right]$ lactate (expressed as $264 / 261 \mathrm{~m} / \mathrm{z}$ enrichment) measured from 0 to 72 hours after incubation in nonconditioned (NCM) and pancreatic cancer cell line conditioned myoblast supernatants. Values are mean. Standard errors were less than $0.5 \mathrm{mmol} / \mathrm{l}$

\section{Detection of differentially expressed genes}

Trials of hybridisation with the same RNA labelled with $\mathrm{Cy} 3$ and $\mathrm{Cy} 5$ on a microarray slide were used as internal quality controls for the detection of a consistent threshold level. According to these experiments, we adopted a threshold level for the logarithmic transformation of the ratio intensity values of 2.5 . Then, we considered as differentially expressed only those genes whose replicated spots resulted in expression values below -2.5 or above +2.5 , respectively.

\section{RESULTS}

Figure 2 shows mean (SD) values and statistical analysis (repeated measures ANOVA) of glucose concentrations in

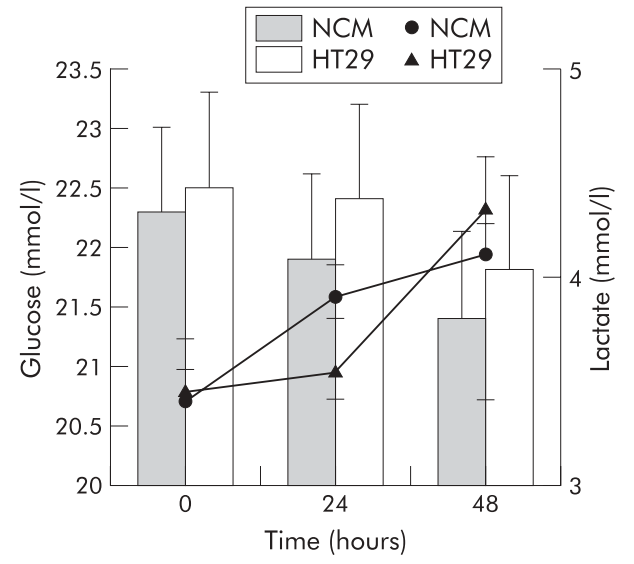

Figure 6 Pattern of glucose (histogram) and lactate (lines) concentrations found in myoblast supernatants after incubation with nonconditioned medium (NCM) or the colorectal cancer cell line HT29 conditioned medium. Values are mean (SD).

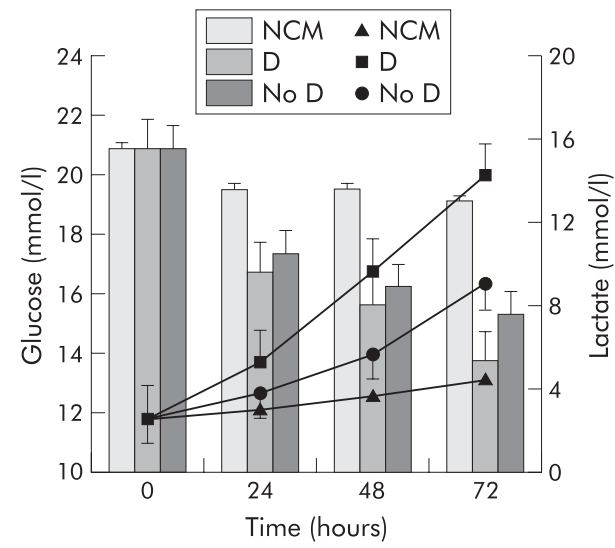

Figure 7 Pattern of glucose (histogram) and lactate (lines) concentrations found in myoblast supernatants after incubation with nonconditioned medium (NCM) or with media conditioned with pancreatic cancer tumour homogenates obtained from patients with (D) or without (No D) type 2 diabetes. Values are mean (SD). Repeated measures analysis of variance: time effects, $p<0.01$ for glucose and $p<0.001$ for lactate; diabetes effects, $p<0.05$ for glucose and $p<0.001$ for lactate; time $\times$ diabetes, $p<0.01$ for glucose and $p<0.001$ for lactate. Bonferroni's $t$ test: $p<0.05 D$ and No $D$ versus NCM for glucose; $p<0.05 D$ versus NCM for lactate.

NCM and pancreatic cancer CM myoblasts, obtained after 24 and 48 hours of incubation, compared with control myoblasts (time 0). Glucose concentrations declined slightly under all experimental conditions with time and were

Table 1 Mean (SD) values and statistical analysis (repeated measures ANOVA) for lactate concentrations in myoblasts incubated with non-conditioned (NCM) and CAPAN-1 or fractioned CAPAN-1 conditioned media (CM)

\begin{tabular}{|c|c|c|c|}
\hline & \multicolumn{3}{|c|}{ Lactate (mmol/I) } \\
\hline & Basal & 24 hours & 48 hours \\
\hline NCM & $3.37(0.2)$ & $3.56(0.33)$ & $4.30(0.52)$ \\
\hline CAPAN-1 CM (*) & $3.20(0.05)$ & $3.90(0.12)$ & $4.96(0.35)$ \\
\hline CAPAN-1 CM >30000 Da (*) & $3.30(0.09)$ & $4.01(0.09)$ & $4.91(0.27)$ \\
\hline CAPAN-1 CM 10-30000 Da & $3.33(0.16)$ & $3.78(0.25)$ & $4.41(0.62)$ \\
\hline CAPAN- 1 CM $<10000 \mathrm{Da}$ & $3.33(0.19)$ & $3.84(0.24)$ & $4.74(0.63)$ \\
\hline
\end{tabular}

For each condition, eight experiments were done.

Repeated measures analysis of variance: time effects, $p<0.001$; cell lines effects, $p<0.05$; time $\times$ cell lines, $\mathrm{p}<0.05$.

Bonferroni's $t$ test: ${ }^{*} p<0.05$ versus NCM. 


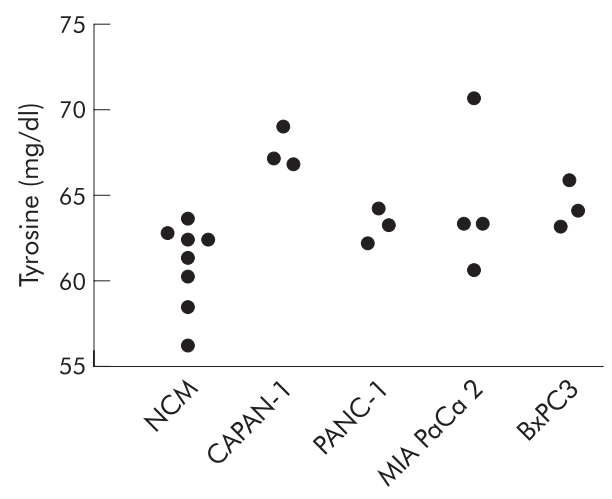

Figure 8 Tyrosine levels measured in supernatants of myoblasts after 48 hours of incubation with non-conditioned medium (NCM) or pancreatic cancer cell line conditioned media. ANOVA one way: $\mathrm{F}=4.23, \mathrm{p}<0.05$. Bonferroni's test for pairwise comparisons: $\mathrm{p}<0.05$ CAPAN-1 versus NCM.

statistically significant in BxPC3 conditioned versus nonconditioned myoblasts after 48 hours of incubation.

Figure 3 reports mean (SD) values and findings at statistical analysis (repeated measures ANOVA) for lactate concentrations in NCM and pancreatic cancer CM myoblasts, obtained after 24 and 48 hours of incubation compared with control myoblasts (time 0 ). Lactate concentration increased in both non-conditioned and pancreatic cancer cell line conditioned myoblasts but the magnitude of this increase was higher in conditioned than in NCM myoblasts (statistically significant in CAPAN-1, PANC-1, and MIA PaCa 2).

Figures 4 and 5 show the pattern of $\left[5_{-13}{ }^{13}\right] /\left[{ }^{12} \mathrm{C}\right]$ glucose (expressed as $247 / 242 \mathrm{~m} / \mathrm{z}$ enrichment) and of $\left[3-{ }^{13} \mathrm{C}\right] /\left[{ }^{12} \mathrm{C}\right]$ lactate (expressed as $264 / 261 \mathrm{~m} / \mathrm{z}$ enrichment) in nonconditioned and pancreatic cancer cell line conditioned myoblasts. The pattern of tracer lactate in conditioned and non-conditioned myoblasts overlapped that of total lactate, indicating that lactate in myoblast supernatants derived from glucose and not from other metabolic substrates.

Table 1 shows lactate concentrations found in myoblast supernatants after incubation with NCM or fractioned CAPAN-1 CM. Lactate significantly increased in supernatants of CAPAN-1 conditioned myoblasts after 24 and, at a higher magnitude, after 48 hours of incubation. Overlapping results were obtained in myoblasts incubated with the two fractions of CAPAN-1 CM with a low ( $<10000 \mathrm{Da})$ and high $(>30000$ Da) molecular weight, but not with the fraction with a molecular weight of $10000-30000 \mathrm{Da}$, although statistical significance was reached only for the high molecular weight CAPAN-1 fraction.

Figure 6 shows mean (SD) values for glucose and lactate concentrations in non-conditioned and colorectal cancer cell line HT29 conditioned myoblasts after 24 and 48 hours of incubation compared with control myoblasts (time 0). No significant difference was found for either analytes (repeated measures ANOVA: NS).

Figure 7 illustrates the pattern of supernatant glucose and lactate concentrations of myoblasts incubated with NCM or medium conditioned with pancreatic tumour homogenates from patient with or without type 2 diabetes. Pancreatic tumour homogenates in the medium of myoblasts caused a significant decline in glucose levels, independent of the presence of type 2 diabetes; lactate concentrations increased in all conditioned myoblasts but significantly in CM tumours from type 2 diabetic patients.

Figure 8 illustrates the pattern of tyrosine concentrations in non-conditioned and pancreatic cancer cell line conditioned myoblasts after 48 hours of incubation. No significant

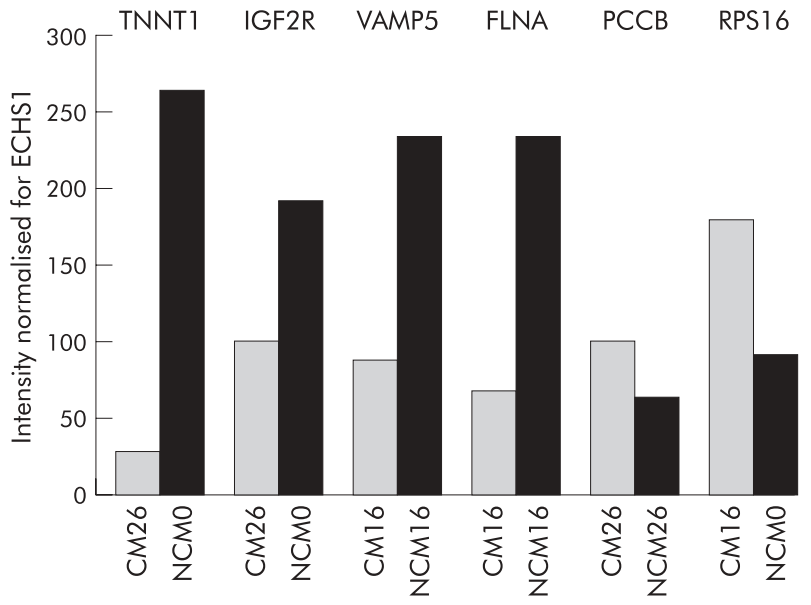

Figure 9 Reverse transcription-polymerase chain reaction results. The housekeeping gene ECHS1 was used as an internal control. Conditioned media (CM) downregulated genes from microarray experiments: TNNT1, IGF2R, VAMP 5, and FLNA. CM overexpressed genes from microarray experiments: PCCB and RPS16. NCM, non-conditioned medium; ECHS1, enoyl coenzyme A hydratase; IGF2R, insulin-like growth factor 2 receptor; VAMP5, vesicle associated membrane protein 5; FLNA, filamin A; PCCB, propionyl coenzyme A carboxylase; RPS16, ribosomal protein $\mathrm{S} 16$.

differences were recorded in tyrosine levels at time 0 (ANOVA one way: $\mathrm{F}=0.38$, NS) or after 24 hours of incubation $(\mathrm{F}=1.09$, NS) (data not shown).

To validate our 3'-cDNA array platform, quantitative RTPCR was undertaken to quantify the level of expression of some muscle transcripts. To this aim, we selected a set of six genes, four of which were underexpressed (TNNT1, IGF2R, VAMP5, FLNA) while two were overexpressed (PCCB and RPS16) in CAPAN-1 conditioned compared with non-conditioned myoblasts, from microarray experiments. The housekeeping gene ECHSI was used as an internal control. We found a correlation between the results of the array analysis and that of RT-PC (fig 9).

Expression levels of several enzymes involved in glycolysis were not altered in CAPAN-1 conditioned compared with non-conditioned myoblasts (hexokinase l (HKl), glycogen synthase kinase 3 alpha (GSK3A), glycogen phosphorylase, pyruvate kinase (PKM2), enolase 3 (ENO3), aldolase A (ALDOA), GAPDH, phosphofructokinase (PFKM), pyruvate dehydrogenase, isocitrate dehydrogenase 2 (IDH2), glycogenin (GYG), isocitrate dehydrogenase 3 gamma (IDH3G), succinyl CoA synthetase, succinate dehydrogenase, malate dehydrogenase $1(\mathrm{MDHl})$, and phosphoglycerate mutase 2 ).

Table 2 reports overexpressed and table 3 underexpressed genes in CAPAN-1 conditioned versus non-conditioned myoblasts. Only genes with a known biological function are reported. Expression levels at 16 or 26 hours in comparison with baseline control myoblasts gave the following results: eight genes were overexpressed, nine genes were underexpressed. Expression levels found in 16 or 26 hour conditioned myoblasts versus those of 16 and 26 hour control myoblasts were as follows: a total of 14 genes were overexpressed and nine were underexpressed in conditioned myoblasts .

\section{DISCUSSION}

It has been suggested that skeletal muscle mass is targeted by tumour derived substances. These can induce glucose intolerance and atrophy, which is responsible, in part, for the marked cachexia and diabetes frequently encountered in pancreatic cancer patients. ${ }^{915}{ }^{18-21}$ We verified the effects of 
Table 2 Overexpressed genes with known biological functions in CAPAN-1 conditioned compared with non-conditioned myoblasts

\begin{tabular}{|c|c|c|c|c|}
\hline & $\begin{array}{l}\text { Muscle cDNA } \\
\text { archive ID }\end{array}$ & Gene names & Biological process & $\begin{array}{l}\text { Expression } \\
\text { ratio }\end{array}$ \\
\hline \multirow{6}{*}{$\begin{array}{l}\text { Overexpressed after } 16 \mathrm{~h} \text { with } \\
\text { respect to } \mathrm{NCM} \text { at time } 0\end{array}$} & 2-001A01 & Ribosomal protein S16 (RPS16) & Protein biosynthesis & 3.72 \\
\hline & 2-007E12 & Fibrillarin (FBL) & rRNA processing & 2.69 \\
\hline & $2-009 C 09$ & APOBEC2 & rRNA processing & 2.50 \\
\hline & $2-026 \mathrm{~B} 06$ & BCL-2 associated athanogene & $\begin{array}{l}\text { Antiapoptosis, cell surface receptor } \\
\text { linked signal transduction }\end{array}$ & 2.57 \\
\hline & 2-031A06 & Transcriptional coactivator (ALY) & Protein complex assembly & 2.42 \\
\hline & 2-039D12 & Peroxisome receptor 1 (PXR1) & Protein-peroxisome targeting & 2.41 \\
\hline \multirow[t]{2}{*}{$\begin{array}{l}\text { Overexpressed after } 26 \mathrm{~h} \text { with } \\
\text { respect to } \mathrm{NCM} \text { at time } 0\end{array}$} & 2-009A02 & PAFAHIB1 & $\begin{array}{l}\text { Neurogenesis, cell motility, lipid } \\
\text { metabolism, signal transduction }\end{array}$ & 3.34 \\
\hline & BL-001H08 & Cathepsin G (CTSG) & Immune response, proteolysis & 5.46 \\
\hline \multirow{7}{*}{$\begin{array}{l}\text { Overexpressed after } 16 \mathrm{~h} \text { with } \\
\text { respect to NCM after } 16 \mathrm{~h}\end{array}$} & 2-001A07 & Alpha one globin (HBA1) & Oxygen transport & 2.84 \\
\hline & 2-005G10 & Isocitrate dehydrogenase 3 beta (IDH3B) & $\begin{array}{l}\text { Isocitrate metabolism, carbohydrate } \\
\text { metabolism }\end{array}$ & 2.95 \\
\hline & 2-015D05 & Ribosomal protein L22 (RPL22) & Protein biosynthesis & 3.06 \\
\hline & 2-022G02 & $\begin{array}{l}\text { ARP1 actin-related protein } 1 \text { homolog A } \\
\text { (ACTRIA) }\end{array}$ & Vesicle transport & 2.55 \\
\hline & $2-034 C 09$ & $\begin{array}{l}\text { U4/U6 associated RNA splicing factor } \\
\text { (HPRP3P) }\end{array}$ & mRNA splicing, mRNA processing & 3.04 \\
\hline & BL-009A02 & Torsin A (DYT1) & Protein folding, heat shock response & 2.95 \\
\hline & BL-010F10 & NFKB2 & Oncogenesis & 3.37 \\
\hline \multirow{7}{*}{$\begin{array}{l}\text { Overexpressed after } 26 \mathrm{~h} \text { with } \\
\text { respect to } \mathrm{NCM} \text { after } 26 \mathrm{~h}\end{array}$} & $2-010 C 12$ & S100 Calcium binding protein A6 (S100A6) & Cell cycle, cell-cell signalling & 2.50 \\
\hline & 2-018A07 & ATP synthase (ATP5B) & Energy pathways & 2.47 \\
\hline & $2-018 \mathrm{CO} 4$ & $\begin{array}{l}\text { Bridging-integrator protein-1 isoform } \\
\mathrm{BIN} 1+12 \mathrm{~A} \text { (BIN1) }\end{array}$ & $\begin{array}{l}\text { Cell cycle control, cell proliferation, } \\
\text { non-selective vesicle transport }\end{array}$ & 3.47 \\
\hline & $2-018 C 10$ & Ribosomal protein S3A (RPS3A) & Protein biosynthesis & 2.63 \\
\hline & 2-021E09 & Ribosomal protein S21 (RPS21) & Protein biosynthesis & 3.42 \\
\hline & 2-028D10 & Propionyl coenzyme A carboxylase & Fatty acid catabolism & 2.61 \\
\hline & BL-003G08 & MEM-102 glycoprotein & Defence response & 3.71 \\
\hline
\end{tabular}

The table lists the transcripts that were found to be upregulated in myoblasts after 16 or 26 hours of incubation with CAPAN-1 conditioned medium in comparison with myoblasts incubated with control medium (NCM).

pancreatic cancer cell conditioned media on glucose metabolism of cultured mice myoblasts and, using a microarray experiment with a platform of 5000 skeletal muscle cDNA, on myoblast gene expression.
Supernatant glucose concentrations slightly declined in conditioned compared with non-conditioned myoblasts, indicating that glucose consumption is higher in conditioned than in non-conditioned myoblasts. The experiments with

Table 3 Underexpressed genes with known biological functions in CAPAN-1 conditioned compared with non-conditioned myoblasts

\begin{tabular}{|c|c|c|c|c|}
\hline & $\begin{array}{l}\text { Muscle cDNA } \\
\text { archive ID }\end{array}$ & Gene name & Biological process & Expression ratio \\
\hline $\begin{array}{l}\text { Underexpressed both after } 16 \\
\text { and } 26 \mathrm{~h} \text { with respect to } \mathrm{NCM} \\
\text { at time } 0\end{array}$ & 2-001H02 & $\begin{array}{l}\text { Ribosomal protein } \mathrm{S} 12 \\
\text { (RPS12 }\end{array}$ & Protein biosynthesis & $-2.96 /-3.93$ \\
\hline \multirow{2}{*}{$\begin{array}{l}\text { Underexpressed after } 16 \mathrm{~h} \text { with } \\
\text { respect to } \mathrm{NCM} \text { at time } 0\end{array}$} & $2-028 \mathrm{H} 06$ & Actin alpha & Control of heart, muscle contraction & -2.75 \\
\hline & $2-029 C 09$ & Sorcin (SR1) & $\begin{array}{l}\text { Control of heart and muscle development, small } \\
\text { molecule transport, intracellular iron storage, } \\
\text { action potential regulation, striated muscle } \\
\text { contraction regulation }\end{array}$ & -2.67 \\
\hline \multirow[t]{6}{*}{$\begin{array}{l}\text { Underexpressed after } 26 \mathrm{~h} \text { with } \\
\text { respect to } \mathrm{NCM} \text { at time } 0\end{array}$} & $2-002 \mathrm{H} 11$ & $\begin{array}{l}\text { Thymosin beta } 10 \\
\text { (TMSB10) }\end{array}$ & Spermatid development & -2.88 \\
\hline & $2-023 F 10$ & Troponin $\mathrm{Tl}$ & Muscle contraction regulation & -4.33 \\
\hline & 2-027F02 & IGF2R & $\begin{array}{l}\text { Signal transduction, receptor mediated } \\
\text { endocytosis }\end{array}$ & -5.44 \\
\hline & 2-029D01 & $\begin{array}{l}\text { Ribosomal protein L14 } \\
\text { (RPL14) }\end{array}$ & Protein biosynthesis & -2.56 \\
\hline & $\mathrm{BL}-010 \mathrm{C} 12$ & PET112L & Protein biosynthesis & -2.73 \\
\hline & $\mathrm{BL}-010 \mathrm{~F} 12$ & $\begin{array}{l}\text { Ribosomal protein L8 } \\
\text { (RPL8) }\end{array}$ & Protein biosynthesis & -3.18 \\
\hline \multirow[t]{4}{*}{$\begin{array}{l}\text { Underexpressed after } 16 \mathrm{~h} \text { with } \\
\text { respect to NCM after } 16 \mathrm{~h}\end{array}$} & 2-010G10 & VAMP5 & $\begin{array}{l}\text { Muscle development, non-selective vesicle } \\
\text { transport }\end{array}$ & -2.53 \\
\hline & $2-017 \mathrm{G} 02$ & $\begin{array}{l}\text { Low density lipoprotein } \\
\text { related protein } 1 \text { (LRP1) }\end{array}$ & Pathogenesis, lipid metabolism, cell proliferation & -2.67 \\
\hline & 2-018F04 & $\begin{array}{l}\text { Endothelial differentiation } \\
\text { related factor } 1 \text { (EDF1) }\end{array}$ & $\begin{array}{l}\text { Developmental processes, cell growth and } \\
\text { maintenance }\end{array}$ & -2.85 \\
\hline & 2-036G04 & $\begin{array}{l}\text { Filamin A, alpha (actin } \\
\text { binding protein 280) } \\
\text { (FLNA) }\end{array}$ & $\begin{array}{l}\text { Neurogenesis, cell motility, cell shape and cell size- } \\
\text { control, actin cytoskeleton reorganisation, cell } \\
\text { surface receptor linked signal transduction }\end{array}$ & -3.26 \\
\hline \multirow{2}{*}{$\begin{array}{l}\text { Underexpressed after } 26 \mathrm{~h} \text { with } \\
\text { respect to NCM after } 26 \mathrm{~h}\end{array}$} & 2-005F09 & NADUFS2 & Complex I (NADH to ubiquinone) & -2.66 \\
\hline & BL-003C11 & $\begin{array}{l}\text { Dual specificity } \\
\text { phosphatase } 1 \text { (DUSP1) }\end{array}$ & Oxidative stress response & -4.01 \\
\hline
\end{tabular}

The table lists the transcripts that were found to be downregulated in myoblasts after 16 or 26 hours of incubation with CAPAN- 1 conditioned medium in comparison with myoblasts incubated with control medium (NCM). 
pancreatic tumour homogenates confirmed and supported this observation. In common with $\mathrm{Li}$ and Adrian, ${ }^{24}$ we found that conditioned myoblasts released higher amounts of lactate in cell culture medium than non-conditioned myoblasts. A very significant increase in lactate production was obtained from myoblasts conditioned with tumour homogenates from diabetic patients, supporting the hypothesis that pancreatic cancer clinically associated with diabetes can cause an increase in lactate production by myoblasts. This finding seems to be peculiar to pancreatic cancer as no effect on glucose or lactate concentrations was found in myoblasts conditioned with a colorectal cancer cell line (HT29).

To confirm that lactate was derived from glucose and not from other metabolic substrates (for example, amino acids), we performed a series of experiments with stable labelled glucose. All lactate derived from glucose, indicating that most of the glucose taken up into the cell was metabolised to lactate rather than undergoing oxidative phosphorylation or being used for glycogen synthesis. The altered glucose metabolism in myoblasts was different from that previously described by us in conditioned hepatocytes where a reduction in lactate production was found. ${ }^{14}$ Tumour products may evoke different metabolic alterations strictly linked to the metabolic pattern of the target cell..$^{25}$

The effect on myoblasts was reproduced not only with the low molecular weight fraction of pancreatic cancer cell conditioned media $(<10000 \mathrm{Da})^{26}$ but also with the fraction with a high molecular weight (>30 $000 \mathrm{Da})$. Two hypotheses may be proposed: (1) in the low molecular weight fraction a "metabolically active" fragment from a larger molecule may be present; and (2) two different molecules may cooperate in modifying myoblast glucose metabolism.

To screen for which muscle genes expression was altered in conditioned myoblasts, we performed an experiment using microarray with a platform of 5000 skeletal muscle cDNA, which was validated by quantitative RT-PCR. In agreement with our hypothesis that glycolysis is not impaired in conditioned myoblasts, expression levels of many genes involved in this metabolic pathway did not vary. In contrast, we found a large number of over- and underexpressed genes in conditioned versus non-conditioned myoblasts (tables 2, $3)$. Some of these genes are potentially involved in modifying glucose metabolism: PCCB and isocitrate dehydrogenase 3 beta (IDH3B) genes, which encode enzymes of the tricarboxylic acid cycle, were overexpressed, and IGFIIR and VAMP5 were underexpressed. Propionyl coenzyme A is derived from oxidation of some amino acids (methionine, isoleucine, and valine) and of unpaired fatty acids ${ }^{27}$ and it is converted into succinyl coenzyme A by PCCB. IDH3B catalyses the oxidative decarboxylation of isocitrate to succinyl coenzyme A via the intermediate alpha-chetoglutarate. We suggest that the mitochondrial tricarboxylic acid cycle could be accelerated, independent of glycolysis, and the production of succinyl coenzyme A enhanced in conditioned versus non-conditioned myoblasts. An accelerated mitochondrial tricarboxylic acid cycle is associated with reduced muscle glycogen synthesis, ${ }^{28}$ an event already described in diabetic pancreatic cancer patients ${ }^{915}$ and it might cause accumulation of ATP and NADH, which are known inhibitors of pyruvate dehydrogenase. ${ }^{27}$ This event may explain the accumulation of lactate observed in our experimental model.

The biological function of the other genes whose expression was altered was not directly or indirectly correlated with lactate production, although some may be associated with insulin secretion and glucose transport. In this context, IGFIIR and VAMP5 downregulation in conditioned myoblasts is of particular interest as IGFIIR binds IGFII and, with less affinity, also insulin and IGFI. ${ }^{29}$ Although the effects of IGFIIR downregulation in muscle tissue are not yet known, it has been reported that glucose increases IGFIIR at the cell surface which promotes insulin exocytosis in insulin secreting cells. ${ }^{30}{ }^{31}$ Alterations in gene expression observed by us may also occur in other target cells: insulin secreting cells, where decreased IGFIIR may reduce insulin secretion, as already been observed in patients with pancreatic cancer. ${ }^{16}$ VAMP5, which belongs to the family of SNARE proteins, may facilitates GLUT4 translocation from the intracellular pool to the plasma membrane. ${ }^{32}$ In this context, downregulation of VAMP5 might determine reduced GLUT4 membranal expression, followed by reduced glucose transport.

Overexpression, observed by us, of some genes involved in intracellular signal transduction, including PAFAHIBI and BCL-2, modifying expression of several ribosomal proteins, may lead to alteration in protein biosynthesis. ${ }^{33-36}$ As we found overexpression in the serine protease, cathepsin $G$, which is involved in connective tissue degradation and caspase activation, ${ }^{37}$ we examined protein catabolism by measuring tyrosine in supernatants as tyrosine rapidly equilibrates between intracellular pools and the medium and is neither synthesised nor degraded. ${ }^{38}$ In our experimental model, tyrosine increased in conditioned myoblasts, indicating that proteolysis overcomes protein synthesis, and this may lead to muscle atrophy. Downregulation of sorcin, actin alpha, troponin $\mathrm{Tl}$, and filamin A may contribute towards this atrophy. ${ }^{39} 40$

In conclusion, our findings demonstrate that pancreatic cancer cell conditioned media enhanced lactate production and induced proteolysis, possibly by altering expression levels of a large number of genes-not only those involved in protein biosynthesis and degradation or glucose metabolism but also those involved in the tricarboxylic acid cycle and in vesicle traffic.

\section{ACKNOWLEDGEMENTS}

This study was supported by Ministero Università e Ricerca (Cofin 2001068593), Rome, Italy. The instrumentation for microarray construction and analysis used for this study were purchased thanks to a generous donation from the Fondazione della Cassa di Risparmio di Padova e Rovigo, Padova, Italy, to the CRIBI Biotechnology Centre. Caterina Millino, Chiara Romualdi, and Milena Bellin are research fellows sponsored by the Fondazione Telethon ONLUS, Italy (grant B.57 to GL).

\section{Authors' affiliations}

D Basso, E Greco, F Navaglia, M Plebani, Department of Laboratory Medicine, University of Padova, Padova, Italy

C Millino, C Romualdi, M Bellin, G Lanfranchi, CRIBI Biotechnology

Centre, University of Padova, Padova, Italy

P Fogar, C-F Zambon, S Pedrazzoli, Department of Medical and

Surgical Sciences, University of Padova, Padova, Italy

A Valerio, A Avogaro, Department of Clinical and Experimental

Medicine, University of Padova, Padova, Italy

N Dussini, Department of Paediatrics, University of Padova, Padova, Italy

\section{REFERENCES}

1 Fogar $\mathbf{P}$, Pasquali $C$, Basso $D$, et al. Diabetes mellitus in pancreatic cancer follow-up. Anticancer Res 1994;14:2827-30.

2 Czyzyk A, Szczepanik Z. Diabetes mellitus and cancer. Eur J Int Med 2000;11:245-52.

3 Gullo L, Tomassetti P, Migliori M, et al. Do early symptoms of pancreatic cancer exist that can allow an earlier diagnosis? Pancreas 2001;22: 210-13.

4 Silverman DT, Schiffman M, Everhart J, et al. Diabetes mellitus, other medical conditions and familial history of cancer as risk factors for pancreatic cancer. Br J Cancer 1999;80:1830-7.

5 Silverman DT. Risk factors for pancreatic cancer: a case-control study based on direct interviews. Terat Carcinogen Mutagen 2001;21:7-25.

6 Lin Y, Tamakoshi A, Kawamura T, et al. Risk of pancreatic cancer in relation to alcohol drinking, coffee consumption and medical history: findings from the Japan collaborative cohort study for evaluation of cancer risk. Int J Cancer 2002;99:742-6. 
7 Gullo L, Pezzilli R, Morselli-Labate AM, and the Italian Pancreatic Cancer Study Group. Diabetes and the risk of pancreatic cancer. N Engl J Med 1994;331:81-4.

8 La Vecchia C, Negri E, Franceschi S, et al. A case-control study of diabetes mellitus and cancer risk. Br J Cancer 1994:70:950-3.

9 Permert J, Adrian TE, Jacobsson P, et al. Is profound peripheral insulin resistance in patients with pancreatic cancer caused by a tumor-associated factor? Am J Surg 1993;165:61-7.

10 Basso D, Brigato L, Veronesi A, et al. The pancreatic cancer cell line MIA PaCa 2 produces one or more factors able to induce hyperglycemia in SCID mice. Anticancer Res 1995; 15:2585-8.

11 Basso D, Valerio A, Brigato L, et al. An unidentified pancreatic cancer cell product alters some intracellular pathways of glucose metabolism in isolated rat hepatocytes. Pancreas 1997;15:132-8.

12 Wang F, Larsson J, Abdiu A, et al. Dissociated secretion of islet amyloid polypeptide and insulin in serum-free culture media conditioned by human pancreatic adenocarcinoma cell lines. Int J Pancreatol 1997;21:157-64.

13 Ding X, Flatt PR, Permert J, et al. Pancreatic cancer cells selectively stimulate islet b cells to secrete amylin. Gastroenterology 1998; 114:130-8.

14 Valerio A, Basso D, Brigato L, et al. Glucose metabolic alterations in isolated and perfused rat hepatocytes induced by pancreatic cancer conditioned medium: a low molecular weight factor possibly involved. Biochem Biophys Res Commun 1999;257:622-8.

15 Liu J, Knezetic JA, Strömmer L, et al. The intracellular mechanism of insulin resistance in pancreatic cancer patients. J Clin Endocrinol Metab 2000;85:1232-8.

16 Basso D, Plebani $M$, Fogar $P$, et al. $\beta$-cell function in pancreatic adenocarcinoma. Pancreas 1994:9:332-5.

17 Mäkimattila S, Hietaniemi K, Kiviluoto T, et al. In vivo glucose-stimulated amylin secretion is increased in nondiabetic patients with pancreatic cancer. Metabolism 2001; 50:1036-42.

18 Todorov P, Cariuk P, McDevitt T, et al. Characterization of a cancer cachectic factor. Nature 1996;379:739-42.

19 Wigmore SJ, Todorov PT, Barber MD, et al. Characteristics of patients with pancreatic cancer expressing a novel cancer cachectic factor. Br J Surg 2000;87:53-8

20 Brown DR, Berkowitz DE, Breslow MJ. Weight loss is not associated with hyperleptinemia in humans with pancreatic cancer. J Clin Endocrinol Metab 2001;86:162-6.

21 Tisdale MJ. Cachexia in cancer patients. Nat Rev Cancer 2002;2:862-71.

22 Avogaro A, Toffolo G, Valerio A, et al. Epinephrine exerts opposite effects on peripheral glucose disposal and glucose-stimulated insulin secretion. A stable label intravenous glucose tolerance test minimal model study. Diabetes 1996:45:998-1007
23 Campanaro S, Romualdi C, Fanin M, et al. Gene expression profiling in dysferlinopathies using a dedicated muscle microarray. Hum Mol Gen 2002;11:3283-98

24 Li J, Adrian TE. A factor from pancreatic and colonic cancer cells stimulates glucose uptake and lactate production in myoblasts. Biochem Biophys Res Commun 1999;260:626-33.

25 Valerio A, Basso D, Mazza S, et al. Serum protein profiles of patients with pancreatic cancer and chronic pancreatitis: searching for a diagnostic protein pattern. Rapid Commun Mass Spectrom 2001;15:2420-5.

26 Basso D, Valerio A, Seraglia R, et al. Putative pancreatic cancer-associated diabetogenic factor: 2030 MW peptide. Pancreas 2002;24:8-14.

27 Stryer L. Biochemistry, 3rd edn., New York: WH Freeman \& Company 1988

28 Dicter N, Madar Z, Tirosh O. a-Lipoic acid inhibits glycogen synthesis in rat soleus muscle via its oxidative activity and the uncoupling of mitochondria. J Nutr 2002; 132:3001-6

29 Fürstenberger G, Senn H-J. Insulin-like growth factors and cancer. Lancet Oncol 2002;3:298-302.

30 Zhang Q, Berggren P-O, Tally M. Glucose increases both the plasma membrane number and phosphorylation of insulin-like growth factor II/ mannose 6-phosphate receptors. J Biol Chem 1997;272:23703-6.

31 Zhang $Q$, Tally $M$, Larsson $O$, et al. Insulin-like growth factor II signaling through the insulin-like growth factor II/mannose-6-phosphate receptor promotes exocytosis in insulin-secreting cells. Proc Nat Acad Sci USA 1997:94:6232-7.

32 Kido Y, Nakae J, Accili D. The insulin receptor and its cellular targets. J Clin Endocrinol Metab 2001;86:972-9.

33 Arai H, Koizumi H, Aoki J, et al. Platelet-activating factor acetylhydrolase (PAF-AH). J Biochem 2002;131:635-40.

34 Jansen B, Zangemeister-Wittke U. Antisense therapy for cancer-the time of truth. Lancet Oncol 2002;3:672-83.

35 Ban N, Nissen P, Hansen J, et al. Placement of protein and RNA structures into a 5 A-resolution map of the 50 S ribosomal subunit. Nature 1999:400:841-7.

36 Kumar KU, Srivastava SP, Kaufman RJ. Double-stranded RNA-activated protein kinase (PKR) is negatively regulated by $60 \mathrm{~S}$ ribosomal subunit protein L18. Mol Cell Biol 1999;19:1116-25.

37 Bird PI. Regulation of pro-apoptotic leucocyte granule serine proteinases by intracellular serpins. Immun Cell Biol 1999:77:47-57.

38 Todorov PT, Deacon M, Tisdale MJ. Structural analysis of a tumor-produced sulphated glycoprotein capable of initiating muscle protein degradation. J Biol Chem 1997;272:12279-88.

39 Berchtold MW, Brinkmeier H, Müntener M. Calcium ion in skeletal muscle: its crucial role for muscle function, plasticity, and disease. Physiol Rev 2000;80:1215-65

40 Maki M, Kitaura $Y$, Satoh $\mathrm{H}$, et al. Structures, functions and molecular evolution of the penta-EF-hand Ca2+-binding proteins. Biochem Biophys Acta 2002;1600:51-60 